\title{
Gender-Specific Differences in Surgical Site Infections: An Analysis of 438,050 Surgical Procedures from the German National Nosocomial Infections Surveillance System
}

\author{
Corinna Langelotz ${ }^{\mathrm{a}}$ Carolin Mueller-Rau ${ }^{\mathrm{a}} \quad$ Stoil Terziyski $^{\mathrm{a}} \quad$ Beate Rau $^{\mathrm{a}} \quad$ Alexander Krannich $^{\mathrm{b}}$ \\ Petra Gastmeier ${ }^{\mathrm{c}, \mathrm{d}}$ Christine Geffers ${ }^{\mathrm{c}, \mathrm{d}}$ \\ ${ }^{a}$ Klinik für Allgemein-, Viszeral-, Gefäß- und Thoraxchirurgie, Charité - Universitätsmedizin Berlin, Campus Mitte, \\ ${ }^{b}$ Abteilung Biostatistik, Koordinierungszentrum für Klinische Studien, Charité - Universitätsmedizin Berlin, Campus Virchow, \\ ${ }^{\mathrm{C}}$ Nationales Referenzzentrum für die Surveillance von nosokomialen Infektionen, \\ ${ }^{\mathrm{d}}$ Institut für Hygiene und Umweltmedizin, Charité - Universitätsmedizin Berlin, Campus Benjamin Franklin, Berlin, Germany
}

Keywords

Surgical site infections - Surveillance $\cdot$ KISS $\cdot$ Gender . Pathogens

\section{Summary}

Background: Surgical site infections (SSI) are among the most frequent healthcare-associated infections. They impose a substantial burden with increased morbidity and exceeding healthcare costs. Risk factors such as age, diabetes, and smoking status are commonly accounted for in the literature, but few studies address gender differences. Methods: Data from the German Nosocomial Infections Surveillance System (Krankenhaus-Infektions-Surveillance-System (KISS)) from 2005 to 2010 were analysed for cardiac, vascular, visceral, and orthopaedic surgery, with a total of 438,050 surgical procedures and 8,639 SSI. Rates of SSI and isolated pathogens were analysed for gender. Results: Women had a lower rate of SSI (SSI/100 procedures) in abdominal surgery than men (2.92 vs. 4.37; $p<0.001$ ). No gender-specific differences were found in orthopaedic and vascular surgery, while women had a higher risk for $\mathrm{SSI}$ in cardiac surgery (5.50 vs. 3.02; $\mathrm{p}<$ 0.001). Isolated pathogens showed differences for sensitive Staphylococcus aureus and Pseudomonas aeruginosa, which were more frequent in women (both $p=0.007$ ), while coagulase-negative staphylococci occurred more often in men (18.8 vs. $14.0 \% ; p<0.001)$. Conclusion: Gender differences in SSI exist and are procedure-specific. The underlying mechanisms need to be further elucidated so that targeted measures for the prevention of SSI can be developed.

\author{
Schlüsselwörter \\ Postoperative Wundinfektionen · Surveillance - KISS · Gender . \\ Pathogene Keime
}

\section{Zusammenfassung}

Hintergrund: Postoperative Wundinfektionen gehören zu den häufigsten nosokomialen Infektionen. Sie sind aufgrund der Erhöhung der Morbidität sowie der Gesundheitskosten von erheblicher Relevanz. Während die Risikofaktoren für Wundinfektionen wie Alter, Diabetes oder Rauchen in der Literatur vielfach adressiert wurden, so liegen kaum Daten zum Einfluss von Gender vor. Methoden: Die Daten des deutschen Krankenhaus-Infektions-Surveillance-Systems (KISS) wurden für kardiochirurgische, gefäßchirurgische, viszeralchirurgische und orthopädische Eingriffe der Jahre 2005-2010 herangezogen. 438050 Prozeduren und 8639 postoperative Wundinfektionen wurden registriert. Die Infektionsraten und isolierte Pathogene wurden in Bezug auf Gender analysiert. Ergebnisse: Die Rate an postoperativen Wundinfektion (Infektionen/100 Operationen) war bei Frauen nach abdominalchirurgischen Eingriffen niedriger als bei Männern (2.92 vs. 4.37; $p<0,001$ ). Es fanden sich keine Unterschiede bei orthopädischen und gefäßchirurgischen Eingriffen, wohingegen Frauen signifikant höhere Infektionsraten nach kardiochirurgischen Eingriffen hatten (5.50 vs. 3.02; $p<0,001)$. Bei den isolierten pathogenen Keimen zeigte sich eine erhöhte Rate von sensiblem Staphylococcus aureus und Pseudomonas aeruginosa bei Frauen (beide $p=0,007$ ). Koagulase-negative Staphylokokken hatten bei Männern einen höheren Anteil (18.8 vs. 14.0\%; $p<0,001$ ). Schlussfolgerung: Gender-Unterschiede in postoperativen Wundinfektionen existieren und sind von der Art des chirurgischen Eingriffs abhängig. Die zugrunde liegenden Mechanismen müssen weiter analysiert werden, um gezielte Präventionsmaßnahmen für das jeweilige Geschlecht ergreifen zu können.

\section{KARGER \\ Fax +497614520714 \\ Information@Karger.com}

www.karger.com
(C) 2014 S. Karger GmbH, Freiburg

$1662-6664 / 14 / 0302-0114 \$ 39.50 / 0$

Accessible online at:

www.karger.com/vim
Dr. med. Corinna Langelotz

Klinik für Allgemein-, Viszeral-, Gefäß- und Thoraxchirurgie

Charité - Universitätsmedizin Berlin, Campus Mitte

Charitéplatz 1, 10117 Berlin, Germany

corinna.langelotz@charite.de 


\section{Introduction}

All patients undergoing surgery are at risk of complications causing significant postoperative morbidity. Surgical site infections (SSI) are among the most common healthcare-associated infections, closely followed by urinary tract infections and pulmonary infections [1]. SSI are not only a cause of considerable discomfort for the patient, but they are also costly, being associated with longer postoperative hospital stays, additional surgical procedures, and often higher mortality.

Rates of SSI vary widely regarding hospital and surgical procedure and may be influenced by surgical management as well as other aspects of the quality of healthcare [1-4].

The rate of SSI has been proposed as a potential indicator of the quality of clinical care and management. There is clear evidence that monitoring of hospital-acquired infections is useful not only to establish surveillance but also to take appropriate measures in order to improve the quality of care [3]. It could be shown that an active surveillance can reduce the incidence of SSI [5].

The risk of developing SSI is also influenced by individual patient characteristics, type of surgery, and causative pathogens and is not exclusively caused by external factors such as clinical management [6-8].

Faraday et al. [9] could show in a prospective study published in Annals of Surgery in 2013 that a past history of skin infections even remote from the site of surgery is a predisposing factor for the occurrence of SSI. Adjustments for intraoperative infection risk factors and adherence to infection control best practice metrics had no impact on risk estimates. The authors also showed in their study on 613 patients that female patients had a reduced hazard ratio of 0.57 for SSI. This factor was not further specified or discussed in their publication. Very few data exist on the impact of gender with regard to the occurrence of SSI. In the study by Brandt et al. [5], demonstrating the beneficial effect of surveillance on rates of SSI, male sex was identified to have an increased odds ratio (OR) for SSI of 1.4 in appendectomies, 1.3 in colonic surgery, 1.2 in hip prosthesis arthroplasty, 1.7 in nephrectomy, and even 2.7 in thyroidectomies. In contrast, reduced ORs for SSI in men were noted for coronary artery bypass (0.6) and herniorraphy (0.4) [5].

The extensive Health Technology Assessment by Gibbons et al. [8] on the identification of risk factors for SSI from 2011 also addressed gender. They concluded in their analysis of 113,824 surgical procedures from the UK National Surgical Site Infection Surveillance Service that the odds for SSI clearly increased with age, but were most varied for gender. Differences could be found for female patients with lower risks of SSI after knee prosthesis procedures and open fracture reduction, while women after coronary artery bypass surgery had higher odds of SSI. The risk for large bowel operations and subsequent SSI was only slightly lower in women [8].

Therefore, it seems mandatory to further evaluate the question of gender as a potential risk factor for SSI.

\section{Material and Methods}

The German National Nosocomial Infections Surveillance System (Krankenhaus-Infektions-Surveillance-System (KISS)) has been performing active surveillance since its establishment in 1997. It consists of different modules for surveillance of healthcare-associated infections, one being the surgery module (OP-KISS) which registers 32 types of surgical indicator procedures on a patient-based voluntary surveillance method with over 600 participating departments. KISS uses definitions of the Centers for Disease Control and Prevention [10]. Details of the methodology of OP-KISS have been previously described [2]. Data from four categories of the surgery module, i.e. orthopaedic, abdominal, cardiac, and vascular surgery, were gathered from the data pool, comprising a total of 438,050 surgical procedures which were monitored between 2005 and 2010. SSI rates were calculated with respect to gender and type of surgery and tested for statistical significance using the statistical software R 3.0.2.

\section{Results}

Among all monitored surgical procedures within the German National Nosocomial Infections Surveillance System from 2005 to 2010 were 438,050 cardiac, vascular, abdominal, and orthopaedic procedures. Within these four groups a total of 8,639 SSI were registered. The general rate of SSI amounted to $1.97 / 100$ procedures.

Of the 438,050 operated patients, 241,437 were female (55\%) and 196,613 male (45\%). The overall rate of SSI for women was $1.74 / 100$ procedures, whereas in male patients SSI occurred in 2.26/100 surgeries. This difference is highly significant with $\mathrm{p}<0.001$ (table 1 ). Since rates of SSI vary considerably with the type of surgery, SSI were calculated separately for orthopaedic, abdominal, cardiac, and vascular surgery.

In orthopaedic surgery, male patients underwent a total of 96,221 procedures $(38.6 \%)$, with the majority of patients being women with 153,111 (61.4\%) procedures. No statistical difference could be shown for gender, with men suffering from SSI in 1.01/100 procedures and women in $0.96 / 100$ of the cases $(p=0.27)$.

In abdominal surgery, the rates of operations between the sexes were similar to orthopaedics, i.e. $40.7 \%$ of the patients were men and $59.3 \%$ women, with 111,053 procedures being performed. However, the occurrence of SSI was significantly lower in women with a rate of 2.92/100, while men developed SSI in $4.37 / 100$ of the cases $(\mathrm{p}<0.001)$.

The opposite results were found in cardiac surgery, where the majority of the 46,277 patients were male $(77.9 \%)$. The SSI rate for men was 3.02/100 procedures, whereas women, accounting for only $22.1 \%$ of the cases, developed SSI in $5.5 / 100$ procedures $(\mathrm{p}<0.001)$.

In vascular surgery, men were also more frequently operated on, accounting for $61.1 \%$ of the 31,388 cases. However, the rates of SSI in males and females did not differ (2.11 and 2.01/100 surgeries, respectively).

The underlying pathogens were isolated in 7,168 of the occurring cases of SSI (3,422 in men and 3,746 in women) (table 2). 
Table 1. Registered procedures from the German Nosocomial Infections Surveillance System (2005-2010) and gender-specific rates of SSI

Table 2. Isolated pathogens of registered SSI from the German Nosocomial Infections Surveillance System (2005-2010) and genderspecific rates

\begin{tabular}{|c|c|c|c|c|c|}
\hline \multirow{2}{*}{$\begin{array}{l}\text { Type of } \\
\text { surgery }\end{array}$} & \multicolumn{2}{|l|}{ Operated patients } & \multicolumn{2}{|c|}{$\mathrm{SSI} / 100$ procedures } & \multirow{2}{*}{$\begin{array}{l}p \text { values }{ }^{a} \\
\text { for SSI }\end{array}$} \\
\hline & male & female & male & female & \\
\hline Orthopaedic & $96,221(38.6 \%)$ & $153,111(61.4 \%)$ & $969(1.01)$ & $1,472(0.96)$ & 0.27 \\
\hline Abdominal & $45,162(40.7 \%)$ & $65,891(59.3 \%)$ & $1,973(4.37)$ & $1,923(2.92)$ & $<0.001$ \\
\hline Cardiac & $36,048(77.9 \%)$ & $10,229(22.1 \%)$ & $1,090(3.02)$ & $563(5.50)$ & $<0.001$ \\
\hline Vascular & $19,182(61.1 \%)$ & $12,206(38.9 \%)$ & $404(2.11)$ & $245(2.01)$ & 0.58 \\
\hline Total & $196,613(44.9 \%)$ & $241,437(55.1 \%)$ & $4,436(2.26)$ & $4,203(1.74)$ & $<0.001$ \\
\hline
\end{tabular}

aPearson's Chi-squared test with Yates' continuity correction.

\begin{tabular}{llrl}
\hline Pathogens & \multicolumn{2}{l}{ SSI with specific pathogens } & \multirow{2}{*}{ p values $^{\mathrm{a}}$} \\
\cline { 2 - 3 } & male $(\mathrm{n}=3,422), \%$ & female $(\mathrm{n}=3,766), \%$ & \\
\hline Staphylococcus aureus - MSSA & $806(23.6)$ & $979(26.1)$ & 0.013 \\
Staphylococcus aureus - MRSA & $213(6.2)$ & $249(6.6)$ & 0.487 \\
Enterococcus spp. & $801(23.4)$ & $808(21.6)$ & 0.067 \\
Escherichia coli & $725(21.2)$ & $801(21.4)$ & 0.862 \\
Coagulase-negative staphylococci & $645(18.8)$ & $524(14.0)$ & $<0.001$ \\
Enterobacter & $189(5.5)$ & $207(5.5)$ & 0.963 \\
Pseudomonas aeruginosa & $182(5.3)$ & $258(6.9)$ & 0.007 \\
Klebsiella spp. & $138(4.0)$ & $156(4.2)$ & 0.825 \\
\hline aPearson's Chi-squared test with Yates' continuity correction. & \\
\hline
\end{tabular}

Staphylococcus aureus was the most frequently isolated pathogen, and its sensitive strain (methicillin-sensitive $S$. aureus (MSSA)) occurred more often in women than in men ( $\mathrm{p}$ $=0.013)$.

No difference could be found in the methicillin-resistant strain (MRSA), where men and women showed percentages of 6.2 and 6.6 for MRSA-SSI, respectively ( $p=0.497$ ).

Enterococci, as the second most frequently isolated organism, did not differ between SSI in men and women with 23.4 and $21.6 \%$, respectively $(\mathrm{p}=0.067)$.

Infections with coagulase-negative staphylococci (CoNS) dominated in men, amounting to $18.8 \%$ of the microbiologically confirmed SSI versus $14.0 \%$ in women $(\mathrm{p}<0.001)$.

No gender differences were present in infections with Escherichia coli, Enterobacter, or Klebsiella. Pseudomonas aeruginosa, however, showed a higher incidence in women than in men (6.9 vs. $5.3 \% ; \mathrm{p}=0.007)$.

\section{Discussion}

With more than 10 million surgical procedures being annually performed in Germany, the excess healthcare costs due to SSI are immense. Any achievable reduction of the rate of SSI is of the utmost benefit for the individual patient as well as the public. Therefore, it is worthwhile to analyse gender differences in the occurrence of SSI in order to evaluate options for targeted preventive strategies.

Looking at the overall rate of SSI determined in this study, with women having significantly lower infection rates as com- pared to men, one might be inclined to relate this to the evolutionary differences between the sexes, known as Bateman's principle. It states that selection favoured an improved immune function in females in order to ensure reproduction and that the male immune suppression is the immunological cost of increased sexual activity [11]. As an alternative hypothesis it was argued that Bateman's principle does not dictate a fixed pattern but favours phenotypically plastic reproductive strategies so that neither sex is expected to possess an intrinsically superior immune function, rather showing varying immunological sex differences in response to different environments.

With reported sex disparities in inflammation, Pergola et al. [12] could show on a hormonal level that testosterone suppresses phospholipase D. This causes sex differences in leukotriene biosynthesis in human monocytes, which are central effector cells in immunity [12]. Romana-Souza et al. [13] demonstrated in their study that gonadal hormones differently modulate cutaneous wound healing, with androgens contributing to stress-induced impairment of the healing, whereas oestrogens did not. Androgens were shown to have a proinflammatory effect on wounds, impairing re-epithelialization, whereas oestrogens had an antiinflammatory effect, with males and females responding differently with regard to stress [13]. A study on plasminogen-deficient mice demonstrated marked gender effects on wound healing [14]. Loss of plasmin-dependent fibrinolysis leads to abnormal wound healing and development of pseudomembranes. An accelerated wound closure was seen in female mice versus male plasmin-deficient mice. Interestingly, this gender effect could not be reversed by ovariectomy, suggesting that female sex hormones did not mediate the accelerated skin wound healing. 
The above studies provide some explanations for the observed lower rates of SSI in female patients; however, looking at the different types of surgery, this is only applicable to abdominal surgery. The exact opposite was observed for women in cardiac surgery, with a much higher risk of wound infections.

Apparently, the gender differences are far more complex in order for one simplistic explanation being able to provide an answer to all disparities.

A highly interesting study by Dos Santos and Monte-AltoCosta [15] published in 2013 showed that female, but not male mice exhibited delayed cutaneous wound healing following aspirin administration. Female mice treated with aspirin had lower oestradiol levels than the control group [15]. This could be a possible underlying mechanism for the elevated rate of SSI in women undergoing cardiac surgery, since most patients receive aspirin for cardiac protection.

It remains unexplained why there were no differences in the rates of SSI to be noted for orthopaedic or vascular surgery in our study. Data from the UK surveillance system showed a decreased risk of SSI for knee prostheses and open reductions of fractures for female gender, but no effect on hip prostheses [8]. Their data did not exhibit a gender difference in vascular surgery either.

Since age is a known risk factor for SSI, it is worth noting that recent research revealed gender-specific changes in the ageing of the human immune system. Marttila et al. [16] performed transcriptional analyses of mononuclear cells from elderly individuals and showed a clear gender bias in comparison to young controls. Of the signalling pathways affected by ageing only 29 were changed in males, whereas 48 pathways were changed in females. This highlights that there are combinatorial effects of age and gender [16].

Concerning the different isolates of pathogens of SSI, significant differences could be found for the sensitive strain of $S$. aureus, being more frequently isolated in women in our study, whereas CoNS had a higher rate in men (18.8 vs. $14 \%)$. $P$. aeruginosa, on the other hand, was more prevalent in women in our analysis. A current review on gender differences in the immune response to infection by McClelland and Smith [17] cited literature stating that $S$. aureus and $P$. aeruginosa had a higher prevalence in men. However, since no general susceptibility of one gender compared to the other with a specific microbial type can be found, the authors concluded that gender-specific differences are quite complex and that there is an interaction between gender and specific immune responses to specific microbes.

\section{Conclusion}

Gender differences in SSI exist, are procedure-specific, and can change in the ageing immune system. The underlying causes of specific risks for SSI need to be further analysed with regard to the complex interaction of gender, type of procedure, age, and pharmacologic interventions so that targeted measures for prevention can be developed for each sex.

\section{Disclosure Statement}

The authors declared no conflicts of interest.

\section{References}

1 Behnke M, Hansen S, Leistner R, Pena Diaz LA, Gropmann A, Sohr D, Gastmeier P, Piening B Nosocomial infection and antibiotic use. A second national prevalence study in Germany. Dtsch Artzebl Int 2013;110:627-633.

2 Gastmeier P, Behnke M, Breier AC, Piening P, Schwab F, Dettenkofer M, Geffers C: Nosokomiale Infektionsraten: Messen und Vergleichen. Bundesgesundheitsbl 2012;55:1363-1369.

$\checkmark 3$ European Centre for Disease Control: ECDC Report. Surveillance of Surgical Site Infections. 2011. www.ecdc.eu.

$\checkmark 4$ Haustein T, Gastmeier P, Holmes A, Lucet JC, Shannon RP, Pittet D, Harbarth S: Use of benchmarking and public reporting for infection control in four high-income countries. Lancet Infect Dis 2011;11:471-481.

5 Brandt C, Sohr D, Behnke M, Daschner F, Rüden $\mathrm{H}$, Gastmeier P: Reduction of surgical site infection rates associated with active surveillance. Infect Control Hosp Epidemiol 2006;27:1347-1351.

6 Owens CD, Stoessel K: Surgical site infections: epidemiology, microbiology and prevention. J Hosp Infect 2008;70:3-10.
7 Weigelt JA, Lipsky BA, Tabak YP, Derby KG, Kim M, Gupta V: Surgical site infections: causative pathogens and associated outcomes. Am J Infect Control 2010;38:112-120.

8 Gibbons C, Bruce J, Carpenter J, Wilson AP, Wilson J, Pearson A, Lamping DL, Krukowski ZH, Reeves BC: Identification of risk factors by systematic review and development of risk-adjusted models for surgical site infection. Health Technol Assess 2011;15:1-15.

9 Faraday N, Rock P, Lin EE, Perl TM, Carroll K, Stierer T, Robarts P, McFillin A, Ross T, Shah AS, Riley LH, Tamargo RJ, Black JH, Blasco-Colmenares E, Guallar E: Past history of skin infections and risk of surgical site infections after elective surgery. Ann Surg 2013;257:150-154.

$\checkmark 10$ Horan TC, Gaynes RP, Martone WJ, Jarvis WR, Emori TG: CDC definitions of nosocomial surgical site infections, 1992: a modification of CDC definitions of surgical wound infections. Infect Control Hosp Epidemiol 1992;13:606-608.

11 McKean KA, Nunney L: Bateman's principle and immunity: phenotypically plastic reproductive strategies predict changes in immunological sex differences. Evolution 2005;59:1510-1517.
12 Pergola C, Rogge A, Dodt G, Northoff H, Weinigel C, Barz D, Rådmark O, Sautebin L, Werz O: Testosterone suppresses phospholipase D, causing sex differences in leukotriene biosynthesis in human monocytes. FASEB J 2011;25:3377-3387.

13 Romana-Souza B, Assis de Brito TL, Pereira GR, Monte-Alto-Costa A: Gonadal hormones differently modulate cutaneous wound healing of chronically stressed mice. Brain Behav Immun 2014;36: 101-110.

14 Rønø B, Engelholm LH, Lund LR, Hald A: Gender affects skin wound healing in plasminogen deficient mice. PLoS One 2013;8:e59942.

15 dos Santos JS, Monte-Alto-Costa A: Female, but not male, mice show delayed cutaneous wound healing following aspirin administration. Clin Exp Pharmacol Physiol 2013;40:90-96.

16 Marttila S, Jylhävä J, Nevalainen T, Nykter M, Jylhä M, Hervonen A, Tserel L, Peterson P, Hurme M: Transcriptional analysis reveals genderspecific changes in the aging of the human immune system. PLoS One 2013;8:e66229.

17 McClelland EE, Smith JM: Gender specific differences in the immune response to infection. Arch Immunol Ther Exp 2011;59:203-213. 